\title{
SINKHOLE HAZARD MAPING WITH THE USE OF SPATIAL ANALYSIS AND ANALYTICAL HIERARCHY PROCESS IN THE LIGHT OF MINING-GEOLOGICAL FACTORS
}

\author{
Agnieszka A. MALINOWSKA and Anna MATONÓG \\ AGH University of Science and Technology, Faculty of Mining Surveying and Environmental Engineering, Department of Mining Areas \\ Protection, Geoinformatics and Mining Surveying, Al. A. Mickiewicza 30, 30-059 Kraków, Poland
}

*Corresponding author'se-mail: amalin@agh.edu.pl, anna.matonog@gmail.com

\begin{tabular}{l}
\hline ARTICLE INFO \\
\hline Article history: \\
Received 28 June 2016 \\
Accepted 14 December 2016 \\
Available online 22 December 2016 \\
\hline Keywords: \\
Sinkhole \\
Hazard assessment \\
Risk factors \\
Uncertainty of data \\
Kernel density interpolation \\
Fuzzy membership function \\
Analytic Hierarchy Process (AHP) \\
Geographical information system (GIS)
\end{tabular}

\begin{abstract}
The problem of sinkhole hazard estimation in the former and present mining areas still remains unsolved. This issue is frequently associated with numerous factors causing that phenomenon. The origin of that factor is not only related to the mining and geological condition of the rock masses in the vicinity of sinkhole. The correct interpretation of grounds for discontinuous deformation occurrence in a given area is particularly important in densely built-up areas. The analyses presented were focused on the identification of risk factors which may have influence on the process of discontinuous deformation occurrence and their spatial analysis. Fuzzy set theory and kernel density estimation support dealing with uncertainty of potential risk factors. The correlation has been established between distribution of this factors and spatial distribution of places where discontinuous deformations occurred. Four the most significant risk factors were taken into account in order to develop probability maps of sinkhole occurrence. Presented approach is based on analytical hierarchy process, which enables integration of that factors. In the investigation both quantitative and qualitative factors were taken into consideration. While modelling discontinuous ground surface deformations, such an approach allows for consideration of complex mining and geological conditions. The effectiveness of the presented solution was verified by comparing probability maps of sinkhole occurrence with the observed sinkholes.
\end{abstract}

\section{INTRODUCTION}

Sinkholes caused in the course of shallow mining activities create a serious hazard for the ground surface, especially when it is densely developed. The issue of shallow mining-induced hazard has been frequently discussed in many countries all over the World, e.g. Germany, USA, Great Britain, Bosnia and Herzegovina, India, Japan, Australia, Korea, China, Poland (Cabala et al., 2004; Jochymaczyk et al., 2006; Li et al., 2016; Whittaker, 1985). The sinkholes caused by human activity are usually related to shallow mining. The geometry, intensity and rate of occurrence of discontinuous deformations depend on a number of mininggeological factors. Many years' observations revealed that the following factors have the strongest influence on discontinuous deformations (Baryakh and Fedoseev, 2011; Blachowski and Ellefmo, 2012; Chang and Hanssen, 2014; Chudek et al., 1988; Cmiel, 2012; Janusz and Jarosz, 1976; Kowalski, 2005; Kuznetsov and Trofimov, 2012; Malinowska and Dziarek, 2014; Matonóg, 2015; Sroka, 2008; Taheri et al., 2015):
- shallow extraction with caving,

- reactivation of old workings,

- fractures, tectonic dislocations,

- cumulation of extraction edges (horizontal projection),

- reactivation of mine workings to the surface (pit),

- fires in shallow workings,

- extraction under watered overburden,

- $\quad$ intense rain falls (scouring),

- dewatering of rock mass,

- intense tensile strains, quickly manifesting themselves on the surface,

- seismic phenomena, tremors caused by extraction, vibration of ground caused by traffic.

Many of these factors are measurable and can be characterized precisely, e.g. depth of extraction or height of post-extraction void. These data can be presented as vector or raster maps. A lot of above listed factors have qualitative character and are not measurable. They can be labeled as qualitative variables. This means that they can be mapped on the 


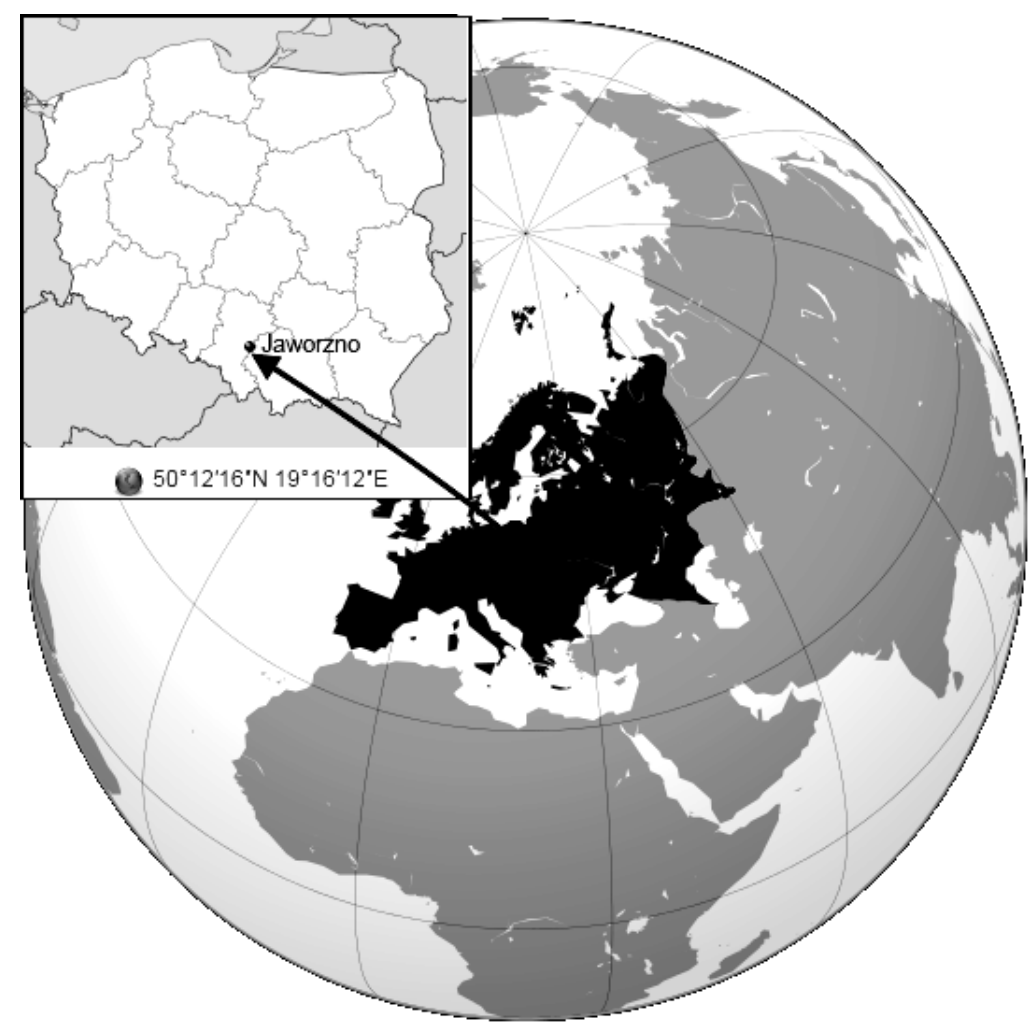

Fig. 1 The study area.

basis of classic measurements. Additionally the factors should be taken into account in view of importance of their impact on the process of discontinuous deformations generation. For instance, in the case of faults their geometry can be described by the angle of dip, throw and run. However these characteristics represent idealized fault components. Unfortunately this information does not suffice to determine the degree to which a fault may contribute to the discontinuous deformations occurrence. The degree of watering of the fault fissure, or the presence of quicksand has a key significance here (Regional Mitigation Action Plan Update, 2012). Therefore additional characteristics of these features should be made. Nevertheless, assessment the influence of such complex tectonic and hydrogeological conditions on the probability of discontinuous deformations development is burdened with high uncertainty. Additional factor which may contribute to sinkhole occurrence are also unfavorable meteorological conditions. During the wet seasons heavy rains cause considerable sinkhole hazard in areas prone to water infiltration from the ground surface to shallow mine workings. In this case the sinkhole hazard will be related to rain falls density, slope of terrain, geomechanical properties of layers in the vicinity of underground workings and complexity of tectonic disturbances in the area of interest (Kowalski, 2005; Baryakh and Fedoseev, 2011; Malinowska and Dziarek, 2013, Taheri et. al, 2015). Hence a question is how to integrate all factors and evaluate their cumulative impact on the sinkhole hazard.
Another problem connected with the evaluation of the discontinuous deformations hazard is the low reliability of information characterizing risk factors. The geological and hydrogeological recognition in the current mining areas is relatively good. In the case of zones mining operation was done at the beginning of the 18th century, the recognition of underground voids geometry is poorer. A similarly the recent geometry of abandoned mine workings done tens of years ago is burdened high. The technical condition and the contraction degree of the mine working, especially the old ones, frequently remain unknown.

This paper is an attempt at integrating both qualitative and quantitative factors which could contribute to the discontinuous deformations occurrence on the surface. With the use of analytical hierarchy process the map of sinkhole hazard was provided. The presented approach may be a starting point for quite a new evaluation of hazards related to discontinuous deformations.

\section{STUDY AREA}

\subsection{OBSERVED DISCONTINUOUS DEFORMATIONS}

The investigation was conducted in an area localized in a Jaworzno town (95,000 of population) south of Poland, with a typical spatial development (estate houses and blocks of flats) (Fig. 1).

The problem of the sinkholes occurrence is significant concern mostly for habitants, the local authorities and also mining company operating below the city. Most of the sinkholes occurred in densely 


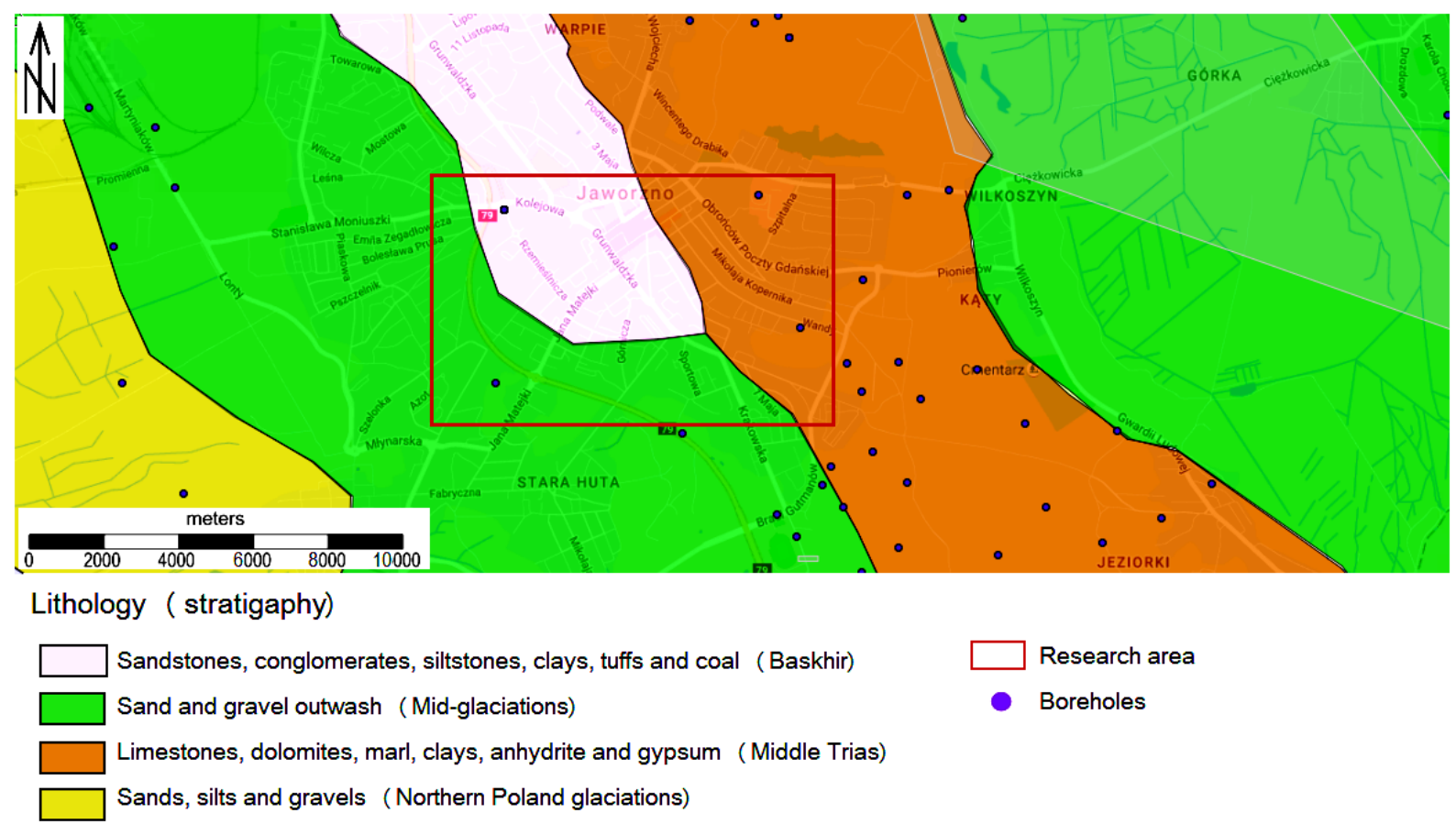

Fig. 3 Geological conditions (by CGDB, 2016).

built up terrains causing real threat to habitants of those areas (Fig. 2). Observed 48 discontinuous deformations were regularly measured and cataloged by employees of mining company which was operating in that area (Fig. 2; AMSGD, 2016).

Each deformation was characterized by such parameters as the year of occurrence, volume, area, dimension in horizontal projection and depth of forms. The 20 sinkholes were collapse-sinkholes types, there rest of sinkholes were classifies as subsidence sinkholes. The dimension of the sinkholes oscillates between 0.5 to 4.0 meters. The depth of the sinkholes reached 5 meters. The accuracy of the sinkholes dimension relies on the geodetic equipment used for the measurement. In horizontal plane the accuracy of the sinkholes measurement was from 0.05 to $0.10 \mathrm{~m}$ and in vertical plane from 0.10 to $0.50 \mathrm{~m}$. In the investigation area discontinuous deformation had surface character (e.g. collapse-sinkholes or subsidence sinkholes) and also linear shape (mainly fractures and troughs). The number of sinkholes appeared in a close proximity to others. The discontinuous deformations also happened to occur in the same place and renew after some time. A predominant number of cases appeared in the mininginduced area, the remaining ones stayed within the reach of a deeper coal bed.

\subsection{CHARACTERISTICS OF MINING-GEOLOGICAL CONDITIONS}

The investigation were conducted in the southeast part of the Jaworzno town, over old workings, where hard coal was extracted mainly in the second half of the $19^{\text {th }}$ century and in the first half of the $20^{\text {th }}$ century. The coal seam has a multi-level character in that area. The coal-bearing strata reach $800 \mathrm{~m}$ b.s.l. The geological beds show complicated internal structure, i.e., changes of thickness and angles of dip of particular layers considerably vary (AMSGD, 2016; CGDB, 2016). The dip of the Carboniferous layers changes from flat deposition in the southwest wing to over $20^{\circ}$ in the north and east wing. The west wing of the trough is tilted at $4^{\circ}$ to $10^{\circ}$. The surfaces representing roof of geological Quaternary, Carboniferous strata were interpolated based on geological contour maps delivered by Archive of Mine Survey and Geological Documentation (AMSGD, 2016). The accuracy of spatial distribution of these layers was unknown. The overburden consists of sandstones, sand and gravel outwash and limestones, marls, and clays (Fig. 3).

In the southwest part of the area there are zones where the Carboniferous strata reaches the surface (Fig. 4, CGDB, 2016). According to the tectonic condition in the investigation area, the deposit is divided into several plates with a number of faults with throws from tens to over 100 meters. In the study area there are no significant tectonic disturbances.

Shallow extraction of hard coal with caving was conducted at two levels (level 207 - closer to the surface, level - 208 - deeper one). The average extraction thickness ranged between 1.8 and $4.5 \mathrm{~m}$. The shallowest levels 207 and 208 were extracted at a depth of 160 to $280 \mathrm{~m}$ a.s.l. ((AMSGD, 2016). That meant that the distance between terrain surface and shallowest mine workings was around $50 \mathrm{~m}$. The spatial distribution of mining workings was very complex (Fig. 5). 


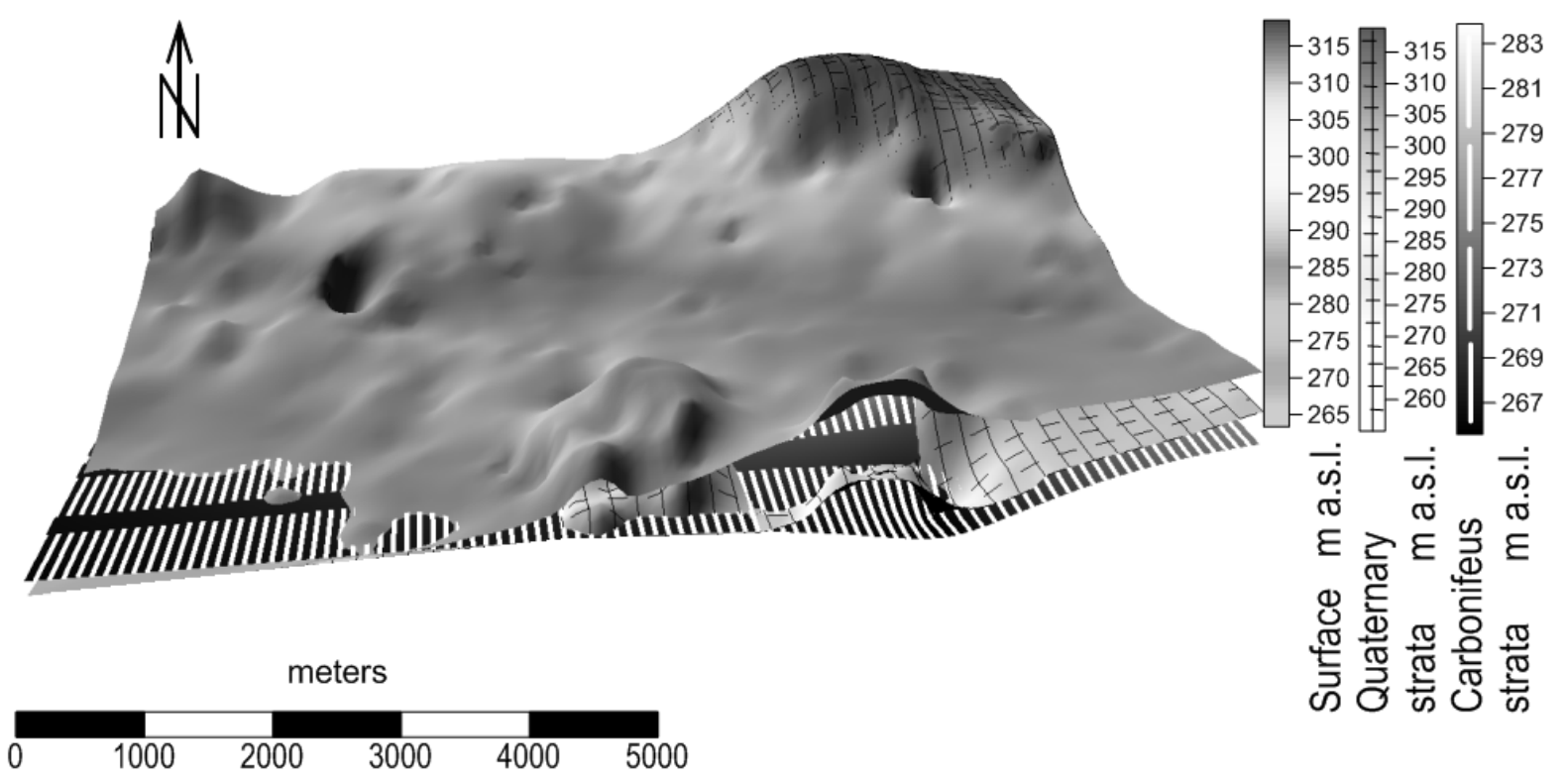

Fig. 4 Distribution of the Carboniferous and Quaternary beds (AMSGD, 2016; CGDB, 2016).

The lower coal beds were extracted at a depth which had no impact on the surface and the surface objects as far as discontinuous deformations were concerned.

\section{METHODOLOGY}

The sinkhole hazard analyses in the mining area mainly relied on analog data (profiles and geological cross-sections, site maps of ground surface with places of discontinuous deformations occurrence) and tabular data (characteristic of recorded tectonic dislocations). This research material was used for analyzing hazard with mining-induced discontinuous deformations based on theoretical considerations (Chudek et al., 1998; Matonóg, 2015). Unfortunately these methods had low prognostic accuracy confirmed by the comparison of the results of theoretical solutions and discontinuous deformations observed in the field. These discrepancies originated from a number of non-measurable risk factors which could not be accounted for hazard evaluation. The considerations made on the basis of the existing prediction methods applied in Poland prove the low efficiency of such solutions because of the big number of factors which had not been accounted for in these methods (Malinowska and Dziarek, 2014; Matonóg, 2015), especially when the post-extraction voids were formed in a distant time perspective and when the present condition of the workings had been poorly recognized. Therefore a deeper analysis of additional factors, which could amplify the discontinuous deformations on the ground surface, should be performed. Another issue is the possibility of predicting linear discontinuous deformations. No such prediction method has been worked out yet in the areas hazarded by sinkholes occurrence above shallow mining workings. This is caused by the fact that the fractures on the surface were frequently originated by qualitative factors, which had not been taken into consideration in the solution. Therefore attempts were made to incorporate in the analyses factors which were the main causes of discontinuous deformations occurrence in many regions, but which had not been taken into consideration in theoretical models.

One of mathematical methods which support complex analysis based on qualitative and quantitative factors is analytic hierarchy process (AHP). The method proposed by Saaty (1980) is commonly applied in order to resolve complex decision problems. The latest research on application AHP method in the Earth Science reveals its high efficiency and validity when compound problem had to be solved.

Analytic hierarchy process has been applied for assessing the landslide susceptibility (Thanh and De Smedt, 2012), for site selection in various industries (Blachowski, 2015; Lamelas et al., 2008), for suitable fire site selection (Pandav et al., 2016). Moreover dealing with uncertain data or subjective factors is often supported by combination fuzzy theory with analytic hierarchy process techniques (Di et al., 2016; Feizizadeh et al., 2015; Leonardi et al., 2016). The AHP has been also successfully applied for sinkhole susceptibility mapping in Iran and Poland (Malinowska and Dziarek, 2014; Taheri et al., 2015).

The proposed framework for sinkhole hazard estimation has been developed based on kernel density estimation, fuzzy sets theory and AHP. The data uncertainty has been taken into consideration by fuzzifying sharp edges of geometrical representation of every risk factor. Analytical hierarchy process supported the integration of all significant risk factor in order to develop final sinkhole hazard map. 

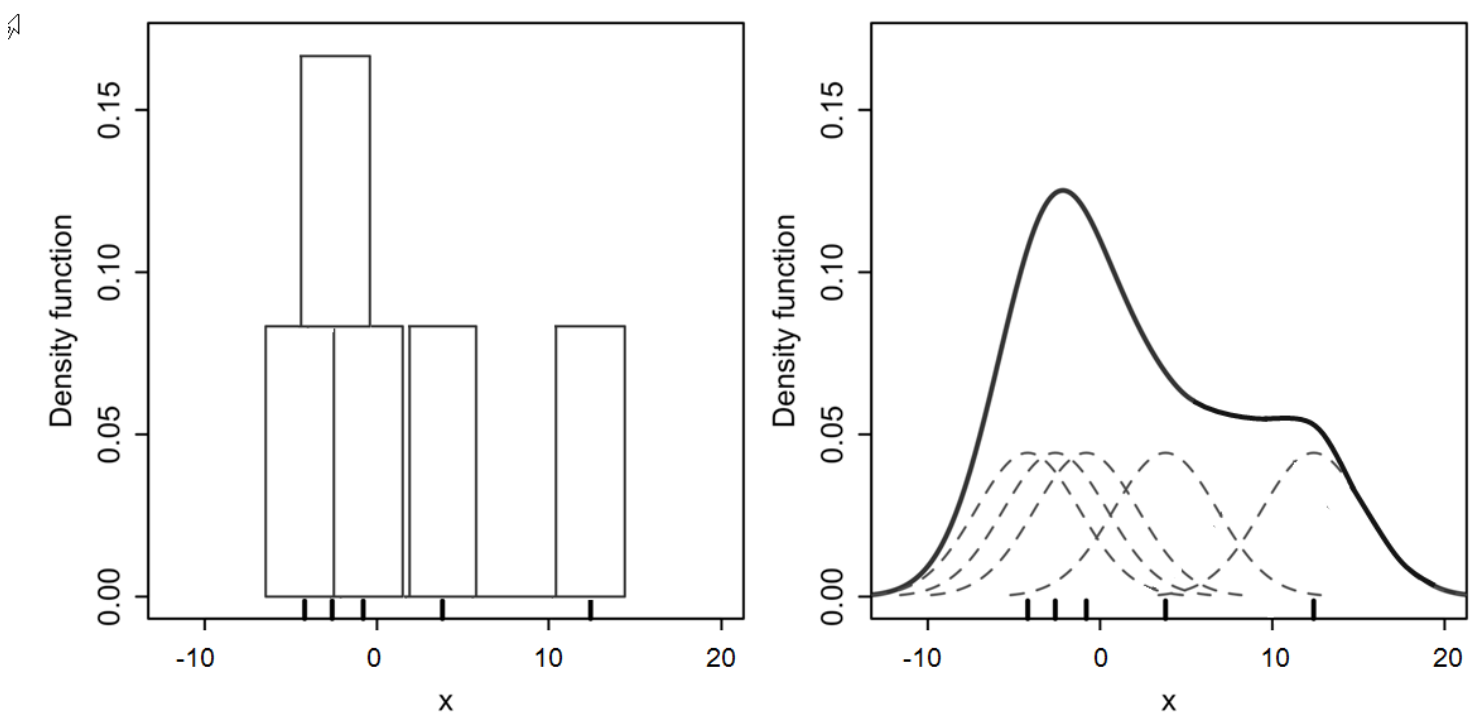

Fig. 6 Comparison of the histogram with kernel density estimate (by Silverman, 1986).

\subsection{KERNEL DENSITY ESTIMATION}

Kernel density estimation is a method applied in order to indentify distribution of spatial patterns of chosen variables (Rosenblatt, 1956; Silverman, 1986; Scott and Terrell, 1987). This class of estimators allows one to non-parametrically determine the density of occurrence of a given random variable. As compared to the parametric estimator, which has strictly defined information about the distribution of a given variable, the non-parametric estimators of this type of information are not required. The histogram is an example of the simplest estimator. A graphical representation of population of a given property in each of the classes is generated for a given variable and the assumed interval of values. Among disadvantages of this approach is discretization of distribution of a given variable, which depends on the defined class interval (Fig. 6 a). The kernel density estimator is a non-parametric solution allowing for the continuous presentation of distribution of a given random variable (Fig. 6 b)

Assuming that $X$ is a d-dimensional independent variable, from an elemental random group $\left(x_{1}, x_{2}\right.$, $\left.\ldots, X_{n}\right)$ having unknown distribution of density $f$, then its kernel estimator $\hat{f}_{h}(x)$ is defined by:

$\hat{f}_{h}(x)=\frac{1}{2} \sum_{i=1}^{n} K_{h}\left(x-x_{i}\right)=\frac{1}{n h^{d}} \sum_{i}^{n} K\left(\frac{x-x_{i}}{d^{d}}\right)$

where:

$X$ - random variable,

$d$-dimension of random variable,

$x_{1}, x_{2}, \ldots, X_{n}$ - random sample variable,

$\mathrm{n}$ - number of analyzed elements,

$\mathrm{h}$ - smoothing coefficient, for $\mathrm{h}>0$,

$\mathrm{K}$ - density function called kernel

$K: \mathbb{R}^{n} \rightarrow[0, \infty)$ meeting the condition:
$\int_{\mathbb{R}^{n}} K(x) d x=1$

The kernel density function $\mathrm{K}$ was adjusted to the number of random variable dimensions. Kernel density estimator defined by Epanechnikov was most frequently used for 1-dimensional random variables because of its highest efficiency (lowest mean square error (Epanechnikov, 1969)). This function assumes the following form:

$K(x)=\frac{3}{4}\left(1-x^{2}\right) 1_{\{|x| \leq 1\}}$

The smoothing coefficient was defined on the basis of the cross-validation or plug-in methods for 1dimensional sets (Scott and Terrell, 1987).

\subsection{FUZZY MEMBERSHIP FUNCTION}

Fuzzy functions were defined by Zadeh (1965) as an answer to the lack of mathematical tools for making decisions in uncertainty conditions, dubious conditions and imperfect data. The fuzzy set theory can be used for qualitative, not quantitative characteristics.

The basic notion in this theory is a fuzzy set A, in a numerical space $\mathrm{X}$ this is a set of ordered pairs:

$A=\left\{\left(x, \mu_{A}(x)\right) ; x \in X\right\}$

where: $\mu_{A}: X \rightarrow[0,1]$ is a membership function of fuzzy set A.

Fuzzy sets are described by membership functions. In the Boolean logic theory an element $\mathrm{x}$ belongs or does not belong to a fuzzy set; in the fuzzy logic a given element may belong to a fuzzy set only to a certain degree. This degree is defined by a membership function. The shape of the assumed membership function depends on the number of available data 


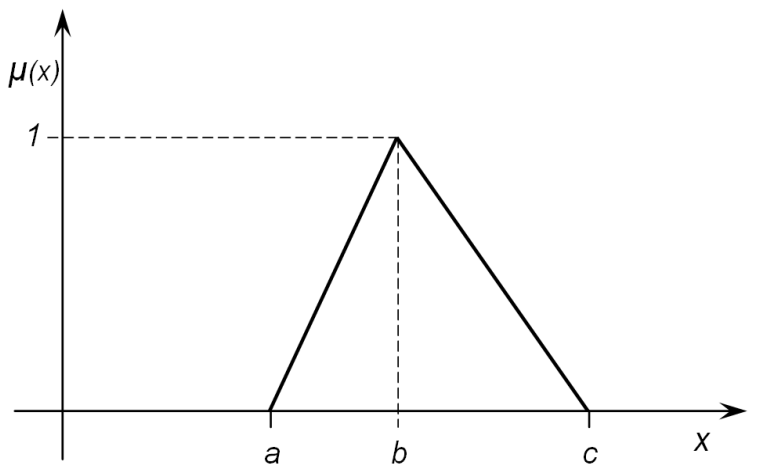

a)

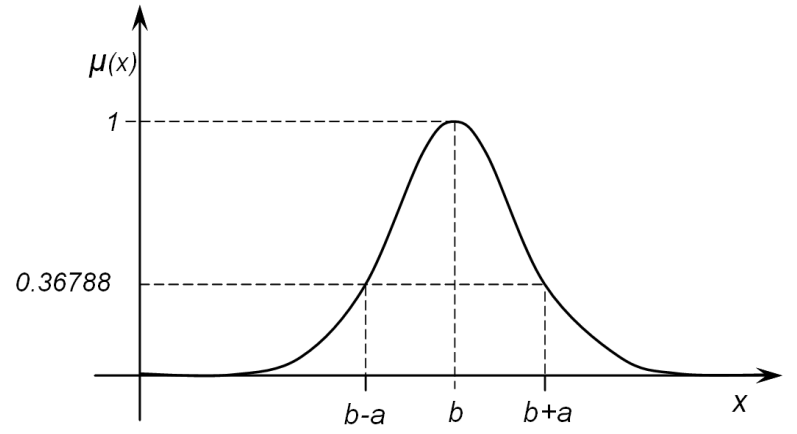

b)

Fig. 7 Triangle and Gaussian membership function (by Zadeh, 1965).

characterizing the course of a given variable (Zadeh, 1965). If the data are scanty, the simplest polygonal functions are selected (Fig. 7 a). When there is more information about data distribution the more complex membership function are applied (Fig. 7 b).

\section{MATERIALS AND RELEVANT CRITERIA}

The discontinuous deformations are influenced by a number of factors related to the geological build of the rock mass, geotechnical properties of the surface ground layers, hydrogeological conditions, dimensions and technical condition of underground voids and other factors connected with the vibration caused by heavy traffic or the terrain shape.

\subsection{INPUT DATA}

The data gathered in order to conduct analysis has quantitative and qualitative characteristics. Moreover the availability and reliability of data vary significantly. The risk factors have different geometry and spatial distribution. The depth of deposition of workings were estimated based on mining maps (contour maps of mining levels 207, 2008), analogously in the place of old mining shafts, which may also be represented by point geometry with additional information about their depth and closing conditions. Underground workings (drifts, mining panels) can be represented by linear or surface geometry, which may be connected with information about their condition (if known), and years of performing them. Geometry of each measurable factor has sharp edges. This approach is frequently burdened with gross simplification in the risk evaluation. Many factors are burdened with high uncertainty, which is connected with their spatial localization or characteristic. For instance, a high uncertainty is connected with the technical condition of underground drifts with timber supports and which were performed many years ago. Another uncertainty comes from the impact of a given factor on the process of discontinuous deformations occurrence. The existing fault with quicksand may cause discontinuous deformations in the outcrop zone. The place of probable occurrence of discontinuous deformations should not be defined by linear geometry (fault outcrop) but by a fuzzy surface. The bigger is the distance from the fault, the lower is the probability of discontinuous deformations occurrence.

\subsection{THE RISK FACTORS INTEGRATION}

The hazard can be graded based on the continuous spatial representation of risk factors. Accordingly, it is purposeful to present the risk factors as continuous surfaces (raster gaphics), simultaneously accounting for the intensity of their occurrence. By blurring sharp edges of the buffer zones (characteristic of their geometry) data uncertainty is taken into consideration in the context of cause-and-effect dependencies, between the distribution of these variables and zones were discontinuous deformations occurred. The further research was done with the use ArcGIS, QGIS and Geomedia Professional (ArcGIS, 2016; QGIS, 2016; Geomedia, 2016).

Finally, following variables has been considered as the most significant risk factors:

- Depth of mining panles-X1

- Density of underground drifts - DUD

- Thickness of loose overburden - TLO

- Mining panels edges overlapping in horizontal projection - MPOHP

- Height of secondary void - HSV

- $\quad$ Presence of mining shafts and pits - PMSP

- Places exposed to traffic-induced vibrations TIV

The risk factors have been labeled form with acronyms in order to simplify understanding of their representation in the analysis. Those factors have been presented in the form of continuous data (rasters, pixel size $10 \times 10 \mathrm{~m}$ ). The raster has been derived with the use of interpolation tools, kernel density estimator and fuzzy logic. Detailed description of data conversion into raster form has been presented below. 


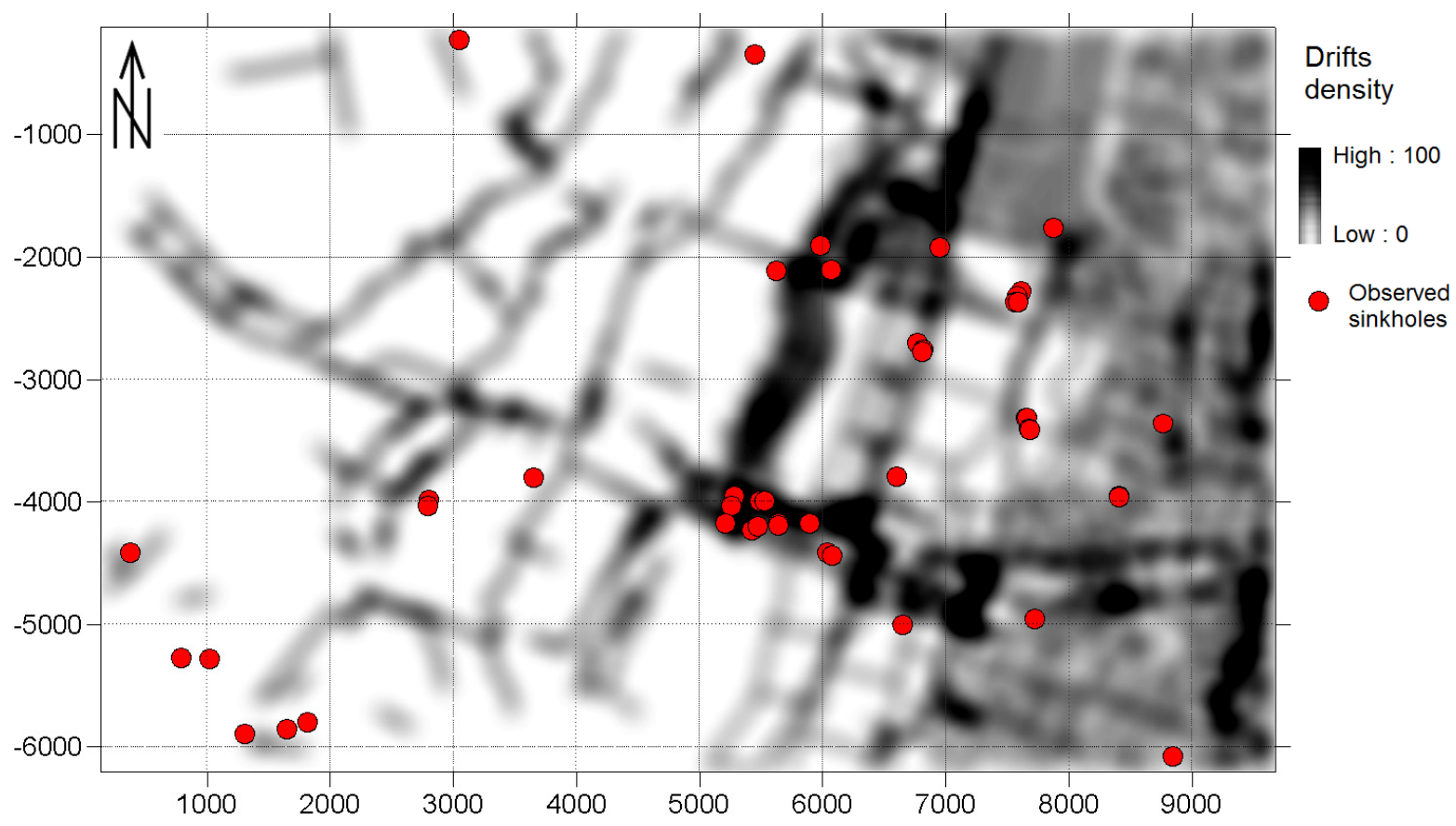

Fig. 9 A raster representation of kernel density map of mining drifts in reference to observed sinkholes.

\section{DEPTH OF MINING PANELS - DMP}

Many years' observations reveal that the deeper is the deposit, the smaller is the probability of sinkhole occurrence (Chudek, 1998; Malinowska and Dziarek, 2014; Whittaker and Reddish, 1989). Two coal beds deposited at small depth below the terrain surface of 50 to $130 \mathrm{~m}$ were analyzed. Analyses were performed only for the beds, whose distance between terrain surface and mining panels did not exceed $100 \mathrm{~m}$. The absolute depth of the workings obtained on the basis of a difference between two rasters: digital terrain model (Fig. 8 a) and digital roof of coal seam (Fig. 8 b). The digital terrain model (DTM) was created based on aerial laser scanning LIDAR done in 2008. The accuracy of vertical distribution of DTM was around $\pm 0.20 \mathrm{~m}$ (CODGIK, 2016). The resolution of interpolated surfaces represented in the raster form had resolution $10 \times 10 \mathrm{~m}$. The digital roof if seam has created based on geological contour maps of Carboniferous strata (AMSGD, 2016). The accuracy of vertical distribution of the coal seam was around \pm 5 m (AMSGD, 2016).

The shallowest part of the deposit was found in the west part of the analyzed area. The distance between ground surface and roof of coal seam was $50 \mathrm{~m}$ and more (Fig. $8 \mathrm{c}$ ).

\section{DENSITY OF UNDERGROUND DRIFTS - DUD}

In the study area mining exploration was driven by number of drifts (Fig. 5; AMSGD, 2016). Most of shallow underground drifts were protected with timber supports in the study area (AMSGD, 2016). In many cases the supports were in a poor technical condition. After a caving takes place in the mine working, the underground voids started to migrate towards the surface. In the place where the drifts occur densely, the rock masses above are significantly disturbed. The probability of occurrence of discontinuous deformations in these zones increases, to decrease with the growing distance from these workings (Fig. 9). The density of underground drifts was presented with the use of the density kernel interpolation. The raster surface value was highest at the location of the drifts (raster pixel value was 100). With the distance from the drifts increase the values of the raster was diminished. The raster values reached zero at the search radius distance from the drifts. The search radius was assumed by the author as $200 \mathrm{~m}$. The highest drifts density occurred in the central zone of the study area (Fig. 9).

\section{THICKNESS OF LOOSE OVERBURDEN - TLO}

Underground post-mining voids created in the deeper excavations are insulated from the surface with a greater number of geological layers and also loose materials of the overburden, which causes that the caving zone reaches the surface more rarely. The physico-mechanical properties of the rock mass differ from deposit to deposit. The risk of deformation occurrence is also influenced by the type of rocks deposited under the overburden. Analogously, the smaller thickness of consolidated strata and loose overburden in a given place, the higher is the probability of discontinuous deformations occurrence. The thickness of loose overburden was estimated as difference between DTM and raster representing the bottom of Quaternary strata. The raster of Quaternary strata was done based on contour maps of that layer (AMSGD, 2016). The thickness of the loose overburden in the center of the study areas equaled to 


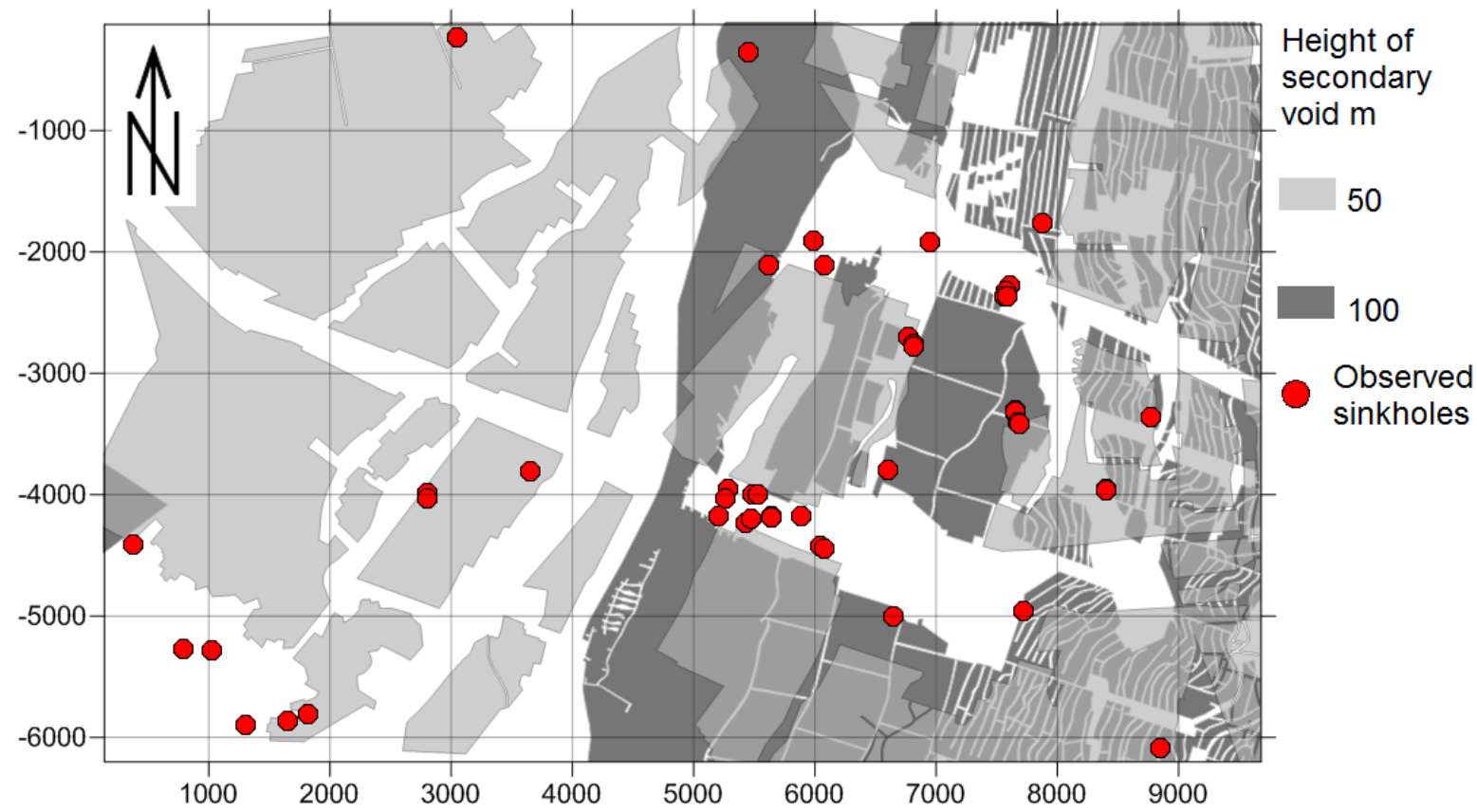

Fig. 11 Height of reclassified secondary void in reference to observed sinkholes.

$0 \mathrm{~m}$, to increase to $13 \mathrm{~m}$ to the southwest and northeast. The final raster representing thickness of loose overburden was reclassified to values from 0 (lack of overburden) to 100 (the thickest overburden).

\section{MINING PANELS EDGES OVERLAPPING IN HORIZONTAL PROJECTION - MPOHP}

The geological condition in the study area was relatively simple. However, the coal seam was extracted in horizontally deposited seams located on below another. Due to that fact, the geometry of mining panels was similar at the successive levels. That caused overlapping of mining panels edges in vertical plane. This cumulation generated additional shear strains, increasing the sinkhole hazard on the surface. The cumulation of mine workings edges was presented in a raster form, on the basis of the kernel density estimation (Fig. 10). In the places where edges were projected on the surface, the probability of discontinuous deformations occurrence was the highest (equal to 100).

\section{HEIGHT OF SECONDARY VOID - HSV}

The dimension and place of occurrence of discontinuous deformations are influenced by the height of the primary void, i.e. most frequently the height of the mining panels $g$ and the percentage of its contraction $a$. The analyses concentrated on the area where the mining operation was done in 1950s. Hence the notion of secondary void, where $g$ is the thickness of primary void $a$ and the percentage of its contraction:

$$
g_{\text {secondary }}=g-g \cdot a
$$

The height of the secondary void was also presented as a continuous raster surface. The height of the secondary void changed from 0.4 to $0.8 \mathrm{~m}$.
The variability of this surface was low. The ultimate raster was presented in the form of a continuous, reclassified surface assuming values from 0 to 100 (Fig. 11). Areas of highest potential thickness of secondary void were ascribed 100 .

\section{PRESENCE OF MINING SHAFTS AND PITS - PMSP}

The frequent cause of discontinuous deformations occurrence, especially in the form of cones, are inactive mining shafts and pits. Vertical excavations were usually closed with sand or other loose material. The gravity and infiltration of water make the rock particles move inside the rock mass and fill the free spaces lower than their original location. In this process a cone or a sinkhole are gradually formed in the mining shaft area. Bearing in mind the fact that coal beds 207 and 208 have been extracted since the second half of the 19th century. The reliability of the mining shaft protection done years ago might be very low. Timber mining shaft supports were most frequently used and in the case of old shallow wells no protection was applied at all. This resulted in increased water infiltration towards excavations, and contributing to scouring. The zone affected by mining-induced surface movements influenced, not only the place where mining shaft was constructed, but also a zone around the mining shafts. This factor was presented with the use of triangle fuzzy sets (Fig. 6 a). The increased risk of discontinuous deformations occurrence was defined in a zone around the mining shafts. The reclassified raster in the place of a mining shaft was ascribed a value of 100 (Fig. 11). With the linear increase of distance from the mining shaft, the risk of sinkhole decreased to zero. 


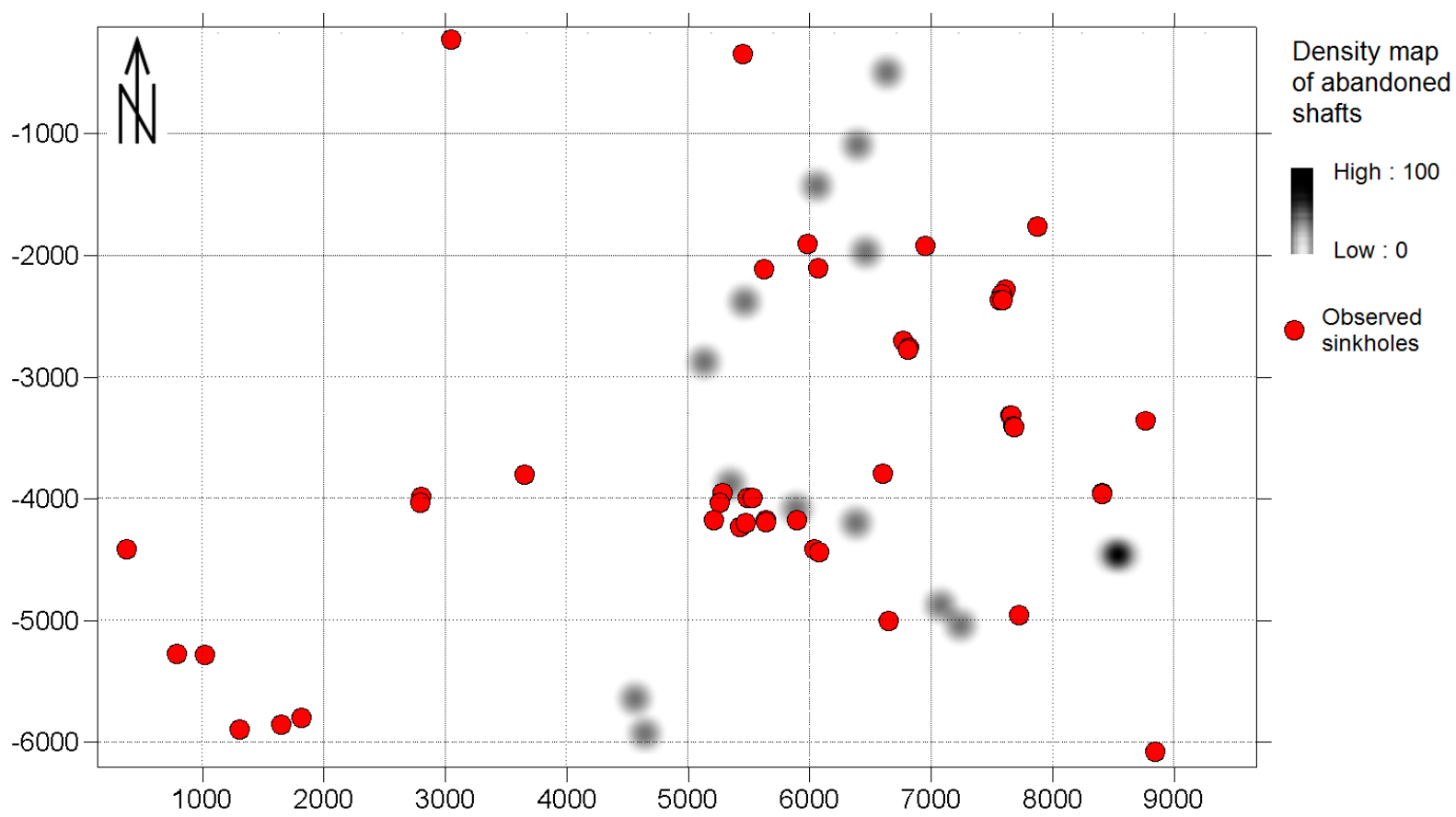

Fig. 12 A raster representation of fuzzy density map of abandoned mining shafts in reference to observed sinkholes.

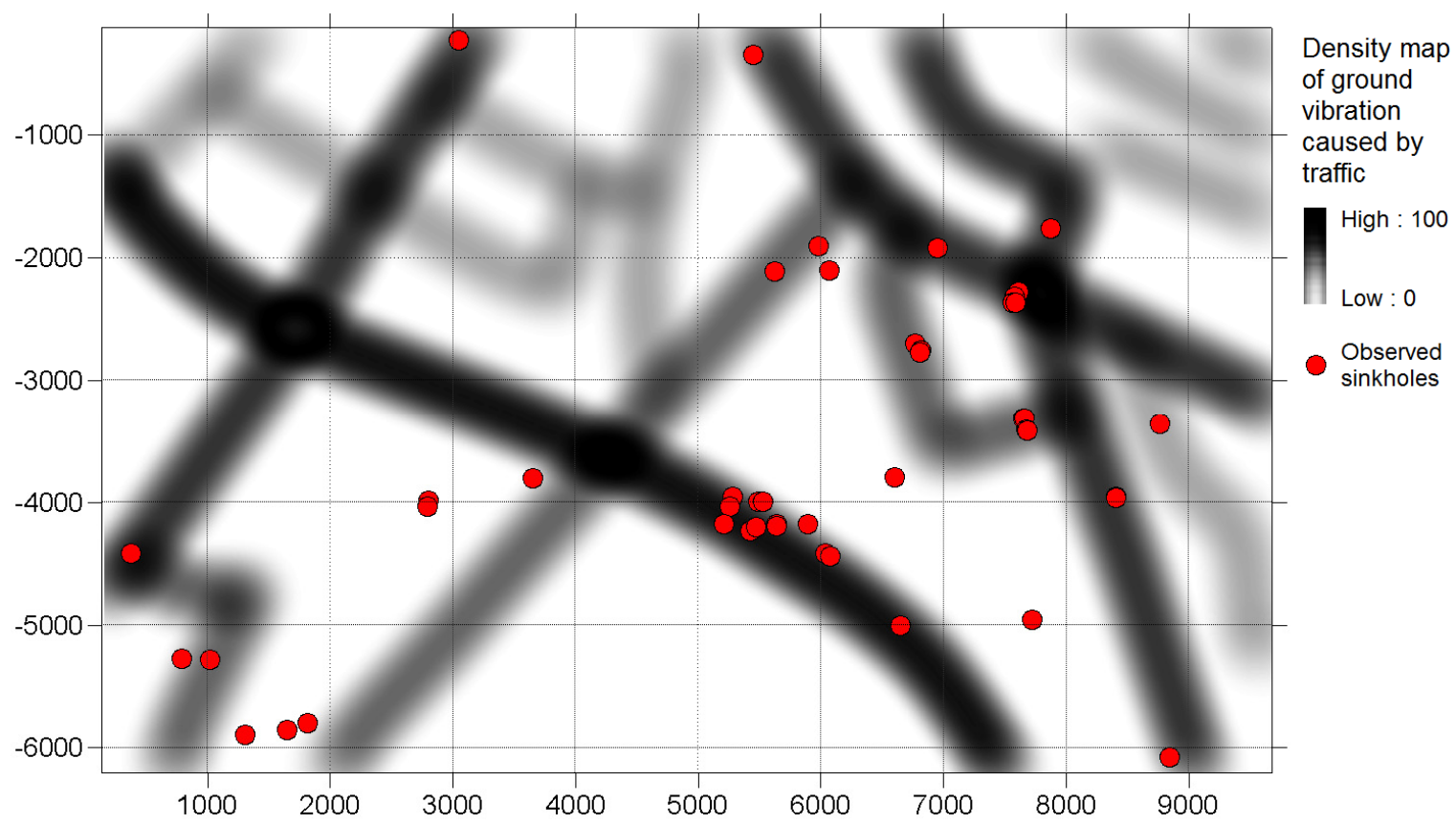

Fig. 13 A raster representation of density map of ground vibration caused by traffic in reference to registered sinkholes.

\section{PLACES EXPOSED TO TRAFFIC - INDUCED VIBRATIONS - TIV}

In the shallow extraction area it is also the vibrations of the surface caused by traffic which are very important (Eleza et al., 2013; Xie and Zhao, 2009). Vibrations of the surface favor the densification of the surface layers and mechanical scouring. A national freeway crossed the analyzed area (Fig. 12).
The roads were ascribed weights to differentiate among the data in view of the traffic intensity in that area. The raster was performed with the use of an estimator of kernel density function and fuzzy logic. In the highest intensity areas were ascribed rasters of 100. 
Table 1 Matrix of risk factor correlation.

\begin{tabular}{llc}
\hline No. & \multicolumn{1}{c}{ Risk factor } & Correlation coefficient \\
\hline 1 & Depth of mining panels-DMP & 0.44738 \\
\hline 2 & Density of underground drifts - DUD & 0.80857 \\
\hline 3 & Thickness of loose overburden - TLO & 0.48082 \\
\hline 4 & Mining panels edges overlapping in horizontal projection - MPOHP & 0.83783 \\
\hline 5 & Height of secondary void - HSV & 0.28427 \\
\hline 6 & Presence of mining shafts and pits- PMSP & 0.42949 \\
\hline 7 & Places exposed to traffic-induced vibrations - TIV & 0.82616 \\
\hline
\end{tabular}

Table 2 Eigenvector estimation.

\begin{tabular}{|c|c|c|c|c|c|}
\hline Factor i & DUD & МРOHР & PMSP & TIV & $\begin{array}{c}\text { Eigenvector (weight) } \\
\mathrm{V}_{\mathrm{Ri}}\end{array}$ \\
\hline Density of underground drifts (DUD) & 1.00 & 0.5 & 4.0 & 7.0 & 0.51 \\
\hline Mining panels edges overlapping (MPOHP) & & 1.00 & 5.0 & 8.0 & 0.33 \\
\hline Presence of mining shafts (PMSP) & & & 1.00 & 3.0 & 0.11 \\
\hline Places exposed to traffic-induced vibrations (TIV) & & & & 1.00 & 0.05 \\
\hline
\end{tabular}

\section{EVALUATION: ANALYTICAL HIERARCHY PROCESS FOR STATISTICALLY SIGNIFICANT RISK FACTORS}

The next stage of the investigation lied in finding statistically significant risk factors causing sinkhole occurrence. A correlation was done among seven relevant risk factors and the raster representing the areas where discontinuous deformations were observed. For the comparison's reason, each of the rasters was reclassified to the values from the interval $0-100$. Normalization was conducted on the basis of the dependence:

$x^{\prime}=\frac{x-x_{\min }}{x_{\max }-x_{\min }}$

A correlation analysis was performed making use of the spatial information about the risk factors. It was based on the raster data. Correlation coefficients were determined for all factors. The correlation of rasters was based on the formula:

$\operatorname{Cov}_{i j}=\frac{\sum_{k=1}^{N}\left(z_{i k}-\mu_{i}\right)\left(z_{j k}-\mu_{j}\right)}{N-1}$

where:

$Z$ - value of raster pixel,

$i, j$ - layers for the respective risk factors,

$\mu$ - mean for each of the layers,

$N$ - number of pixels in raster,

$k$ - number of particular pixel in raster.

Variables, whose spatial raster picture had the strongest correlation with the raster distribution of places where discontinuous deformations were observed, were established on the basis of this correlation of factors (Table 1).

The highest correlation coefficient between the place of discontinuous deformations occurrence and the risk factors was estimated for the following variables: density of underground drifts (DUD), coverage of edges of underground excavations (MPOHP), places exposed to traffic-induced vibrations (TIV). The depth of deposit (DMP) and thickness of loose overburden (TLO) were of less importance. The remaining variable like secondary void (HSV) did not have any influence on the discontinuous deformations development.

Further analyses were made for:

- Density of underground drifts - DUD

- Mining panels edges overlapping in horizontal projection - MPOHP

- Presence of mining shafts - PMSP

- Places exposed to traffic-induced vibrations TIV

The depth of deposition (DMP) and thickness of the loose overburden (TLO) were excluded from the analyses because of very low variability of distribution of these factors. The spatial analysis performed on low variability factors did not allow for determining the significant influence of these variables on the discontinuous deformations occurrence on the surface.

The weighted rasters were used for obtaining a cumulative map of zones with increased probability of discontinuous deformations occurrence. Weights for the four factors (DUD, MPOHP, PMSP and TIV) were established taking into account their significance in the relation to sinkhole process development. The weights were established with the use of Analytic Hierarchy Process (AHP) (Matonóg, 2015; Saaty, 1980). Each element was weighed forming a triangular preference matrix. An assumption was made that each element of the matrix was equivalent to itself (Table 2). The determined weights of elements were expressed as eigenvectors.

When significance of variables was established, every raster was multiplied by assigned weight. Weighted rasters were summarized. The final probability map of discontinuous deformations occurrence was in the form of raster with values from 0 to 100 . Areas prone to sinkhole occurrence have appeared in the eastern part of the study area. In that 
area the mining drifts density was the highest and the distance between the surface and the mining panels was the smallest. The probability of sinkhole occurrence in the areas marked with dark color (Fig. 14). The results of the analyses were confronted with the places where the discontinuous deformations have been already recorded.

The probability of discontinuous deformations occurrence is high in the east zone of the analyzed area. The biggest number of deformations has been observed in the central and east zone. The probability map of deformation occurrence has been classified into 4 classes: low probability $(0-20)$, moderate $(>20$ $40)$, high (>40-75) and very high (>75-100). Most of the sinkholes occurred in areas assigned to high and very high probability classes $(41 \%$ high, $25 \%$ very high). There are also zones where the estimated risk of discontinuous deformations occurrence is high, but discontinuous effects have not been observed there yet. Some of the classified discontinuities appear in an area where the probability of their occurrence is relatively low (23\% for low and $14 \%$ for moderate probability). This can be caused by insufficient recognition of geological conditions in the rock mass, existence of voids of natural and anthropogenic origin, which have not been documented on historical maps. Such factors could lead to the activation of discontinuous deformations on the surface. However, we can venture a statement that in majority of cases the classified phenomena correspond to the prediction. On this basis highly hazarded areas, where no construction activities are recommended for safety reasons, can be distinguished. Attention should be paid to the fact that these analyses are valid only for a specific study area and the obtained results are valid only for the local conditions.

\section{CONCLUSION}

The efficiency of analytical methods used for evaluating hazard of discontinuous deformations occurrence in some mining or post-mining areas is low (Kowalski, 2005; Malinowska and Dziarek, 2013; Sroka, 2008) therefore attempts were made to establish methods of analyzing factors responsible for discontinuous deformations occurrence on the surface. The cause and effect analysis of mining-geological and the discontinuous deformations occurrence were presented in this research. Attention was paid to factors which have not been quantitatively analyzed yet because of their complex character, e.g. density of underground drifts and cumulation of mining panels edges of numerous coal beds. Seven factors presented in the form of reclassified raster (0 to 100) were used for introducing certain gradation of the risk which can be generated by a given factor. The correlation analysis revealed that densification of underground mine drifts, mining panels edges overlapping in horizontal projection, areas of occurrence of mining shafts and pits, as well as vibrations caused by traffic have strongest influence on discontinuous deformations occurrence in the analyzed area. Combining AHP technique with fuzzy sets and kernel density estimation set out an integrated approach to define the hazard condition of sinkholes development. The four maps representing spatial distribution of density of mine drifts (DUD), density of mining panels edges (MPOHP), areas of occurrence of mining shafts and pits (PMSP) and density of vibrations caused by traffic (TIV) with their weights were integrated to generate sinkhole hazard map.

The statistics of classified sinkhole map reveal that $70 \%$ of the total area was found to be under moderate hazard of sinkhole occurrence. The area of high and very high sinkhole hazard was less than $20 \%$ of the total area. The spatial distribution of the sinkhole hazard showed that under significant hazards condition might cause discontinuous deformation in the central-eastern part of the study area. The area under low hazardous condition of sinkhole hazard was distributed mainly in the eastern part of area of interest.

Comparison sinkhole hazard map and the registered ones, revealed high accordance in the central-eastern part of the area. However the reliability of the achieved map in the western part is low. The final sinkhole evaluation only four factors took into consideration. They were depicting mostly hazard related to the shallow, old mining. The information about geological condition in the study area was incomplete, especially the geomechanical parameters of the ground. Due to limited number of risk factors, further validation of presented solution may be needed in the further research.

It should be also emphasized that variables taken into consideration in investigation and their weights are valid only in the area of the research. Nevertheless, the presented approach as a methodology can be also successfully used in other developed areas, which should be particularly protected and monitored because of the high probability of sinkholes occurrence. Especially for the areas in which complex geological and mining conditions hider proper inference about possible sinkhole occurrence done base on rigorous solutions.

\section{ACKNOWLEDGEMENTS}

This research has been financed by the National Center for Research and Development, grant No. UMO-2014/15/B/ST10/04892.

\section{REFERENCES}

Baryakh, A. A. and Fedoseev, A. K.: 2011, Sinkhole formation mechanism. Journal of Mining Science, 47, 4, 404-412. DOI: 10.1134/S1062739147040022

Blachowski, J. and Ellefmo, S.: 2012, Numerical modeling of rock mass deformation in sublevel caving system. Acta Geodyn. Geomater., 9, 3 (167), 379-388.

Blachowski, J.: 2015, Methodology for assessment of the accessibility of a brown coal deposit with Analytical Hierarchy Process and Weighted Linear Combination. Environ Earth Science, 74, 4119-4131. DOI: $10.1007 / \mathrm{s} 12665-015-4461-0$

Cabala, J., Teper, L. and Rutkowski, T.: 2004, Rockmass deformations caused by zinc and lead ores mining in Olkusz Region (Southern Poland). Acta Geodyn. Geomater., 1, 1(133), 47-58. 
Chang, L. and Hanssen, R.F.: 2014, Detection of cavity migration and sinkhole risk using radar interferometric time series. Remote Sensing of Environment, 147, 5, 56-64. DOI: 10.1016/j.rse.2014.03.002

Chudek, M., Janusz, W. and Zych, J.: 1988, Study on recognition of sinkhole occurence process caused by underground mining operations. Zeszyty Naukowe Politechnika Śląska, S. Górnictwo z. 141, (in Polish).

Cmiel, S.R.: 2012, The Upper Silesian coal basin fault zone as a region of high-risk operation. Acta Geodyn. Geomater., 9, 2 (166), 133-136.

Di, Z., Xinping, Y., Jinfen, Z., Zaili, Y. and Jin, W.: 2016, Use of fuzzy rule-based evidential reasoning approach in the navigational risk assessment of inland waterway transportation systems. Safety Science, 82, 352-360. DOI: 10.1016/j.ssci.2015.10.004

Elez, J., Cuezvab, S., Fernandez-Cortesc, A., GarciaAntonc, E., Benaventeb, D., Cañaverasb, J.C. and Sanchez-Moralc, S.: 2013, A GIS-based methodology to quantitatively define an adjacent protected area in a shallow karst cavity: The case of Altamira cave. Journal of Environmental Management, 118, 122-134. DOI: $10.1016 /$ j.jenvman.2013.01.020

Epanechnikov, V.A.: 1969, Non-parametric estimation of a multivariate probability density. Theory of Probability and its Applications, 14, 153-158. DOI: $10.1137 / 1114019$

Feizizadeh, B., Roodposhti, M.S., Jankowski, P. and Blaschke, T.: 2014, A GIS-based extended fuzzy multi-criteria evaluation for landslide susceptibility mapping. Computers \& Geosciences, 73, 208--221. DOI: 10.1016/j.cageo.2014.08.001

Janusz, W. and Jarosz, A.: 1976, Sinkholes caused by shallow underground mining operations. Państwowa Akademia Nauk, Katowice, (in Polish).

Jochymaczyk, K., Cabala, J. and Poręba, A: 2006, Application of resistivity imagining to recognition of geological structure in the area of shallow $\mathrm{Zn}-\mathrm{Pb}$ ore bodies (preliminary study). Acta Geodyn. Geomater., 3, 3 (143), 131-138.

Kowalski, A.: 2005, About occurrence of linear discontinuities on the surface. Safety and protection for mining environment, WUG, 12, 25-32, (in Polish).

Kuznetsov, S.V., and Trofimov, V.A.: 2012, Formation of tension and delamination areas in a long excavation's roof. Journal of Mining Science, 48, 5, 789-797. DOI: $10.1134 / \mathrm{S} 1062739148050036$

Lamelas, M.T., Marimoi, O. and Hoppe, A.: 2008, Suitability analysis for sand and gravel extraction site location in the context of a suitable development in the surrounding of Zaragoza, Spain. Environmental Geology, 55, 1673-1683.

Leonardi, G., Palamara, R. and Cirianni, F.: 2016, Landslide Susceptibility Mapping Using a Fuzzy Approach. World Multidisciplinary Civil EngineeringArchitecture-Urban Planning Symposium. Procedia Engineering, 161, 380-387.

DOI: $10.1016 /$ j.proeng.2016.08.578

Li, Y., Yang, J. and Hu, X.: 2000, Origin of ground fissures in the Shanxi Graben System, Northern China. Engineering Geology, 55, 4, 267-275. DOI: $10.1016 / \mathrm{S} 0013-7952(99) 00082-4$

Malinowska, A. and Dziarek, K.: 2014, Modelling of cavein occurrence using AHP and GIS. Natural Hazards and Earth System Sciences, 14, 8, 1945-1951. DOI: 10.5194/nhess-14-1945-2014

Matonóg, A.: 2015, The risk assessment of discontinuous deformations of land surface taking into account qualitative factors. Master thesis, unpublished, (in Polish).
Pandav, Ch., Sachin, K. Ch., Kiran, M. J., Basanta, M. S. and Prabin, K.: 2016, Application of an Analytic Hierarchy Process (AHP) in the GIS interface for suitable fire site selection: A case study from Kathmandu Metropolitan City. Socio-Economic Planning Sciences, 53, 60-71. DOI: $10.1016 /$ j.seps. 2015.10 .0

Regional Mitigation Action Plan Update: 2012, Hazard Identification

https://www.aacog.com/DocumentCenter/Home/View /4309 (22.11.2016)

Rosenblatt, M.: 1956, Remarks on some nonparametric estimates of a density function. The Annals of Mathematical Statistics, 27, 3, 832-837.

Saaty, T.L.: 1980, The Analytic Hierarchy Process. McGraw-Hill, USA.

Scott, D.W. and Terrell, G.R.: 1987, Biased and unbiased cross-validation in density estimation. Journal of the American Statistical Association, 82, 400, 1131-1146.

Silverman, B.W.: 1986, Density estimation for statistics and data analysis. Chapman and Hall, London.

Sroka, A.: 2008, Designing coal extraction where the surface is threatened by discontinuous linear deformations. Gospodarka Surowcami Mineralnymi, 24, 2/3, 445-455, (in Polish).

Taheri, K., Gutiérrez, K., Mohseni, H., Raeisi, E. and Taheri, M.: 2015, Sinkhole susceptibility mapping using the analytical hierarchy process (AHP) and magnitude-frequency relationships: A case study in Hamadan province, Iran. Geomorphology, 234, 6479. DOI: 10.1016/j.geomorph.2015.01.005

Thanh, L.N. and De Smedt, F.: 2012, Application of an analytical hierarchical process approach for landslide susceptibility mapping in A Luoi district, ThuaThien Hue Province, Vietnam. Environmental Earth Science, 66, 1739-1752. DOI: 10.1007/s12665-011-1397-x

Whittaker, N. and Reddish, D.J: 1989, Subsidence occurrence, prediction, and control: Developments in geotechnical engineering, 56, New York, Elsevier Publishing Co.

Xie, Y.S. and Zhao, Y.S: 2009, Technique of top coal caving with vibration. The 6th International Conference on Mining Science \& Technology. Procedia Earth and Planetary Science, 1, 219-226. DOI:10.1016/j.proeps.2009.09.036

\section{Internet resources}

https://en.wikipedia.org/wiki/Kernel_density_estimation\#/m edia/File:Comparison_of_1D_histogram_and_KDE.pn $\mathrm{g}(01.06 .2016)$

http://www.dziennikzachodni.pl/artykul/928205,dziura-wsosnowcu-na-placu-zabaw-to-biedaszyb-albo-szybkopalni-niwkamodrzejow,id,t.html (01.06.2016)

CGDB (Central Geological Data Base) http://baza.pgi.gov.pl/ (01.06.2016)

CODGIK (The National Geodetic and Cartographic Resources)

http://www.codgik.gov.pl/index.php/zasob/numeryczn e-dane-wysokosciowe.html (01.06.2016)

AMSGD (Archive of Mine Survey and Geological Documentation) http://www.wug.gov.pl/o_nas/archiwum_dokumentacj i $(01.06 .2016)$

ArcGIS

https://www.arcgis.com/features/index.html (01.06.2016)

QGIS

http://www.qgis.org/pl/site/ (01.06.2016)

Geomedia

http://www.hexagongeospatial.com/products/powerportfolio/geomedia $(01.06 .2016)$ 


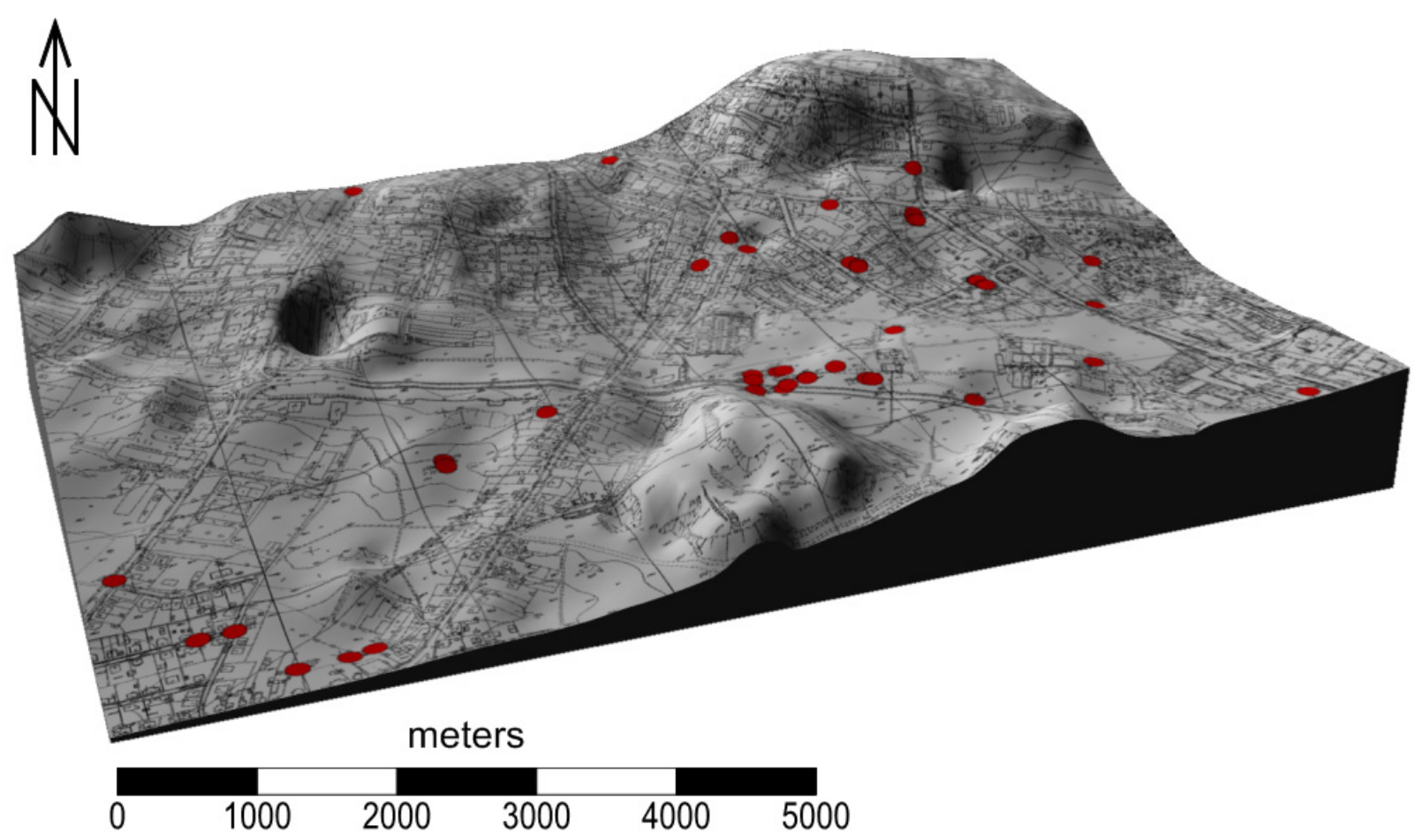

Fig. 2 Recorded discontinuous deformations (red spots) (AMSGD, 2016).

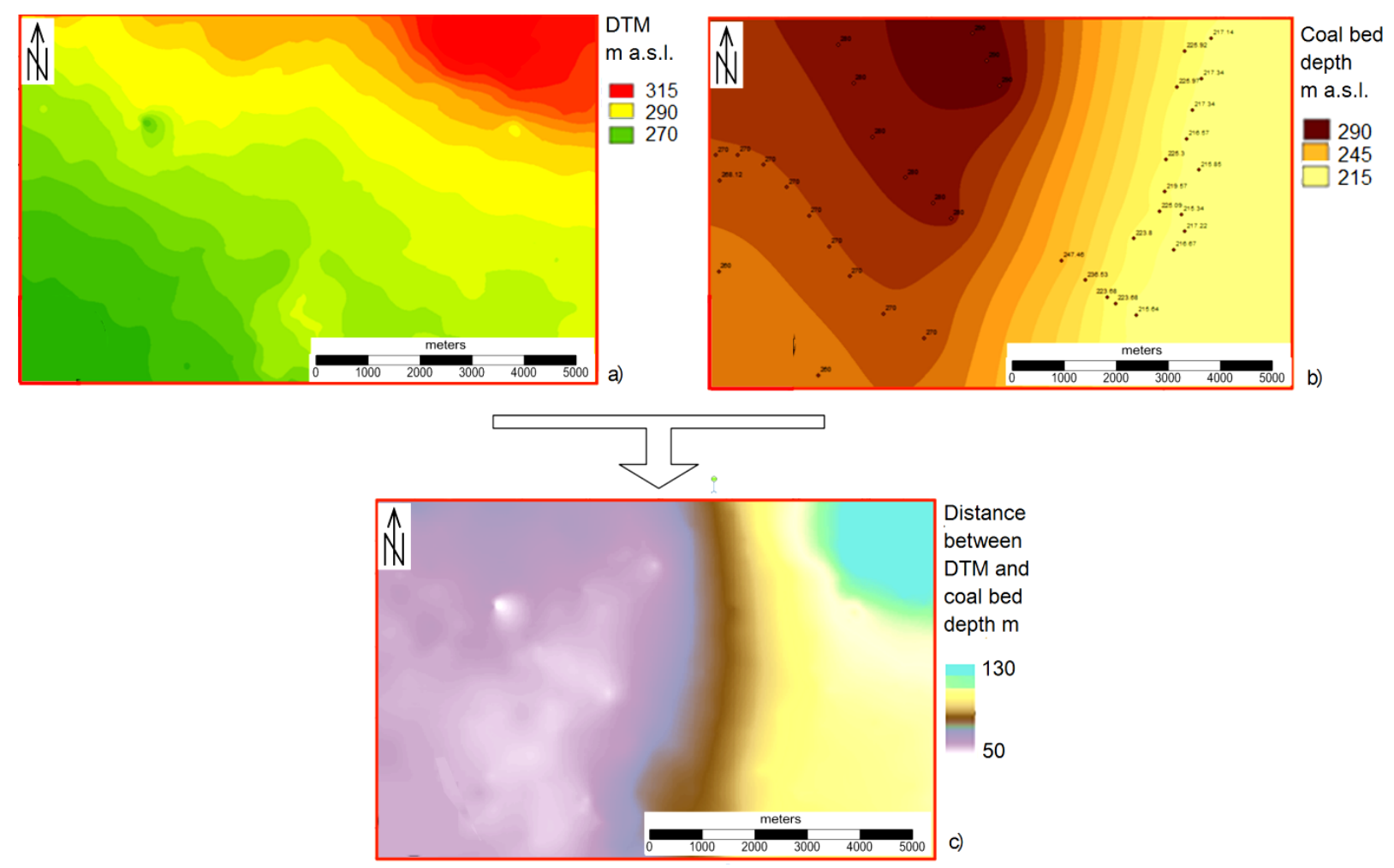

Fig. 8 Depth of seam deposit, a) digital terrain model (CODGIK, 2016), b) digital roof of coal seam (AMSGD.2016). c) the distance between ground surface and coal seam. 


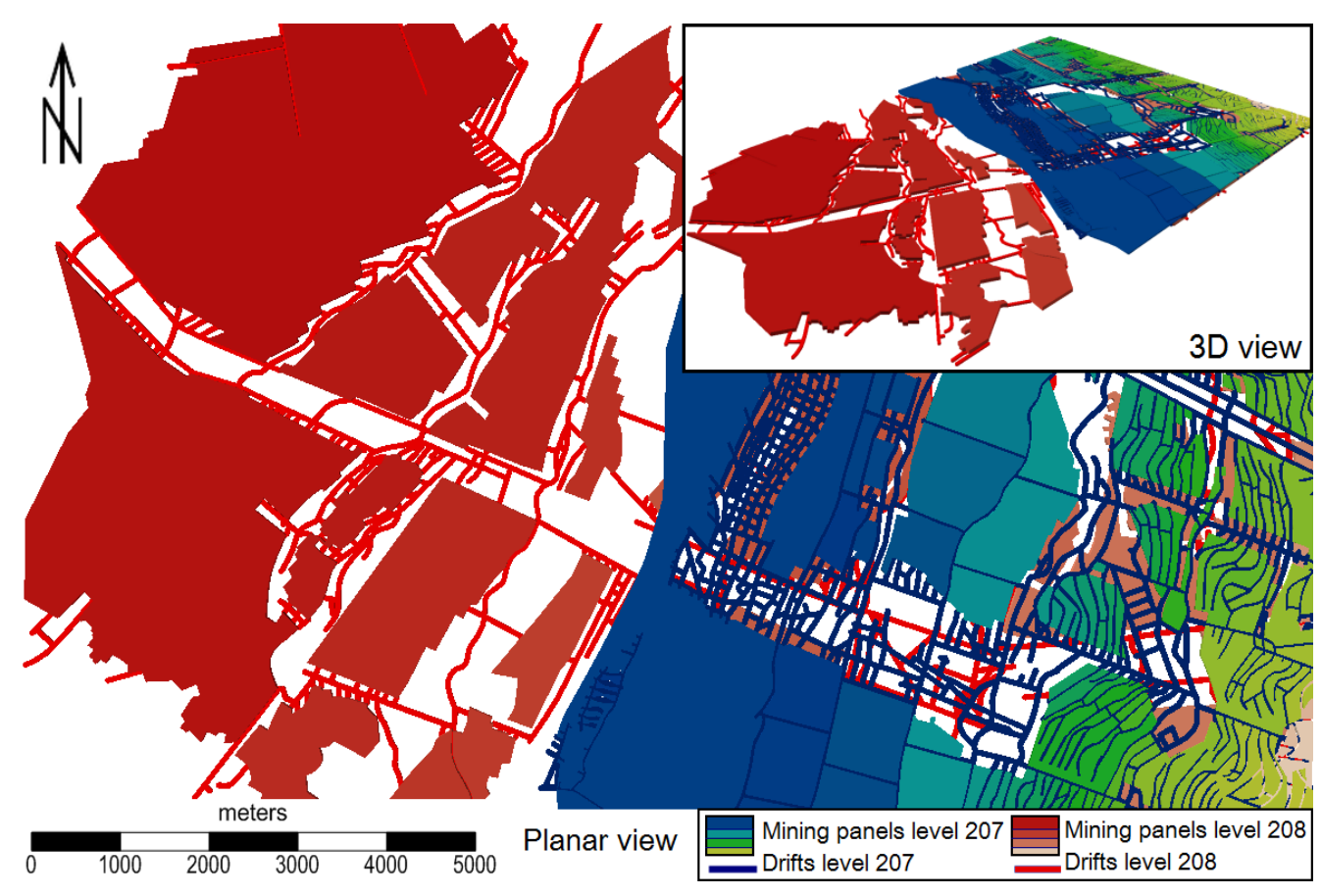

Fig. 5 Spatial distribution of mine underground workings (AMSGD 2016).

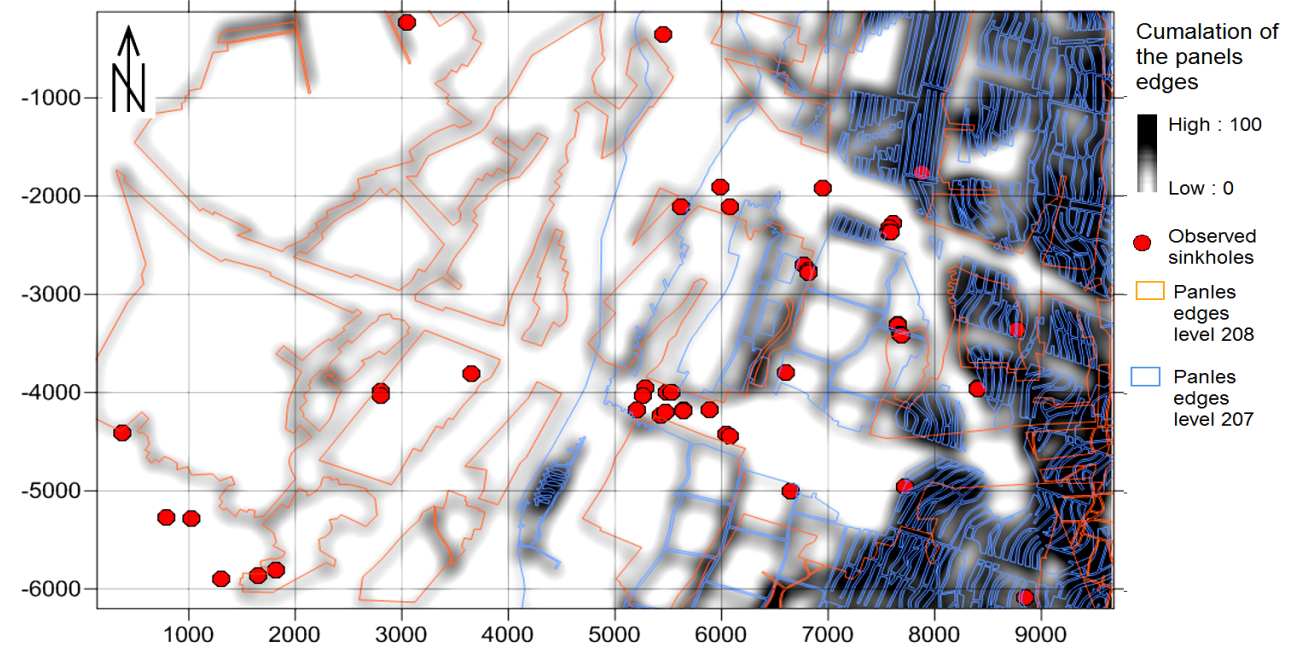

Fig. 10 A raster representation of kernel density map of mining panels edges cumulation in reference to observed sinkholes and mining panel edges.

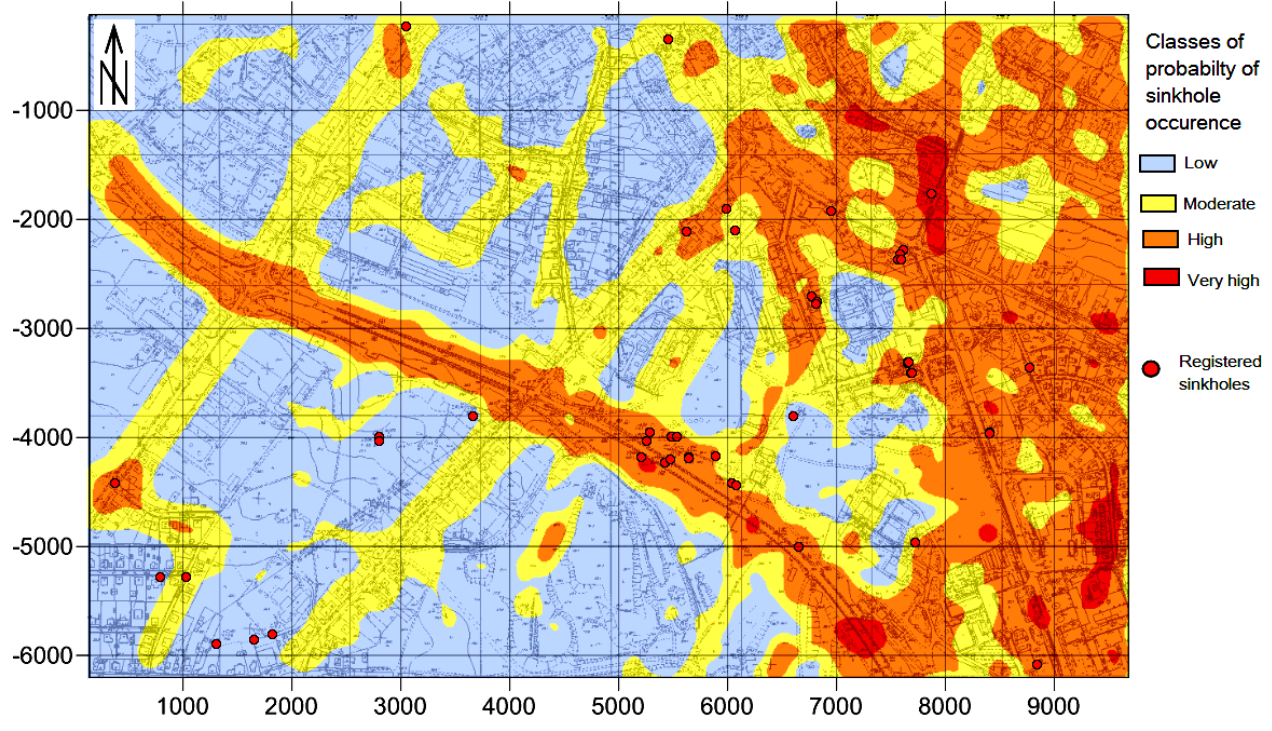

Fig. 14 A raster representation of probability map of discontinuous deformations occurrence in reference to registered sinkholes, 